\title{
Competitive Dynamics between Physical and Virtual Markets in Multiplex Networks
}

\author{
Luisa Díez-Echavarría*, Gerardo Gutiérrez-Gutiérrez², Diana Carolina Ríos-Echeverri \\ 1 Departamento de Finanzas, Facultad de Ciencias Económicas y Administrativas, Instituto Tecnológico Metropolitano, 50004 \\ Medellín, Calle 54 A \#30-01, Colombia \\ 2 Instituto de Física, Universidad de Antioquia, 50004 Medellín, Calle 67 \#53-108, Colombia \\ ${ }^{3}$ Departamento de Ciencias Administrativas, Facultad de Ciencias Económicas y Administrativas, Instituto Tecnológico \\ Metropolitano, 50004 Medellín, Calle 54 A \#30-01, Colombia \\ *Corresponding author, e-mail: luisadiez@itm.edu.co
}

Received: 27 January 2021, Accepted: 09 December 2021, Published online: 03 February 2022

\begin{abstract}
Despite having interesting results of analyzing the adoption of e-commerce using social networks, diffusion does not occur in a single-layered network. There is sufficient evidence that game theory, complex networks and Theory of Planned Behavior are suitable frameworks to represent some part of the dynamics of innovation diffusion. However, it is necessary to integrate this methodological triplet to accept that an emergent behavior is generated by more real causes. We analyzed the effect of the multiplex topology when people decide to make transactions through virtual or physical channels, and found that connectivity is a key issue when managing the agent's behavior. This also translates into greater coordination in the agents' decisions. When a multiplex is formed by at least one network with very efficient information flow, this network will govern the dynamics affecting channel selection and will also reduce transaction uncertainty. In addition, we found that investing in connectivity is worthwhile when trust is low in at least one channel; otherwise, it does not have enough impact to increase current transactions. This article makes a significant methodological contribution by showing a new way to analyze the impact of multiplex social networks, as well as a practical contribution by evidencing the effects of the structures on both intentions and actions.
\end{abstract}

\section{Keywords}

e-commerce, multiplex networks, theory of planned behavior, coordination game

\section{Introduction}

Globalization and the use of information technologies have changed the way companies work. Many of them have a growing interest in the use of e-commerce as a means to carry out commercial transactions, creating opportunities to access new markets and remove disadvantages in terms of size, resources, geographic isolation, and market reach (Aydın and Savrul, 2014; Bánhidi, 2021; DeLone and McLean, 2004; Grandon and Pearson, 2004; Ngai and Wat, 2002; Wymer and Regan, 2005).

As e-commerce adoption continues to grow, so does the need to understand why and how people choose to adopt it (Eastin, 2002). This process has been widely studied using surveys, interviews, and case studies (Wymer and Regan, 2005). Regarding diffusion, adoption has been analyzed on a single social network, but real diffusion phenomena rarely happen this way (Ramezanian et al., 2015; Salehi etal., 2015).
A single person can belong to several social networks at the same time (family, friends, colleagues, etc.) where he/ she exchanges information (Kivelä et al., 2014), and these networks influence the decision due to the need for social acceptance by their community (MacVaugh and Schiavone, 2010). In that sense, these types of diffusion processes can be modeled as a coordination game played on a social network, where there is expected to be a high payoff when there is a match between players decisions and a low payoff when there is no match (Immorlica et al., 2007).

It is also well known that the different structures that networks follow drastically affect the results of the phenomenon (Petridis and Petridis, 2020; Rahmandad and Sterman, 2008). The above is known thanks to the numerous studies that analyze a single network; however, still only a few works cover multilayer networks (Salehi et al., 2015). 
This is why this dynamic must be analyzed through multiplex networks, to understand the behavior closest to reality. In the social sciences, multiplexity refers to the overlapping relations between people, for example, a person has gym friends, work friends, and family, three different networks representing the relations with the same individual (Verbrugge, 1979).

We are interested in three topologies of networks: random, small-world, and preferential attachment. The random network is a random choice between all possible networks between a fixed number of nodes (Erdős and Rényi, 1959). This topology does not represent the characteristics of real networks (Newman, 2003) very precisely. Small-world networks introduced by Watts and Strogatz (1998) are constructed by changing the edges of a regular lattice stochastically. Its first property is that the average shortest path length scales logarithmically with the number of nodes. Real network examples, with the smallworld structure, are scientific collaboration networks (Newman, 2001), the Boston subway network (Latora and Marchiori, 2002), and neural networks (Sporns, 2003). A preferential attachment network is the one that its connectivity follows a power-law distribution. Remarkable networks that present preferential attachment structures are the internet (Faloutsos et al., 1999), most of the cellular networks (Barabási and Oltvai, 2004), and the scientific citation networks (de Solla Price, 1965).

In the process of adoption of innovations, like the online transactions, the relationship between the members of a network can be more critical and influential than factors related to the product or channel (MacVaugh and Schiavone, 2010). Therefore, studies of diffusion of innovations should follow an intention model that includes social influence, like the Theory of Planned Behavior (TPB) (Ajzen, 1991).

TPB explains the social behavior of people through the intention to perform such action. This model (see Fig. 1) is composed of three constructs (or determinants of the intention): attitude towards the behavior (beliefs about the expected results of performing the behavior), subjective norm (what the individual believes other important people to him would think if he/she performed the behavior), and perceived behavioral control (how easy or difficult the individual finds to perform the behavior) (Ha et al., 2012). TPB is a good evaluation engine because it is more robust and detailed in explaining the adoption process than other models proposed in the field (Cadavid, 2015).

Thus, there is sufficient evidence that game theory, complex networks and TPB are suitable frameworks to represent some part of the dynamics of innovation diffusion.

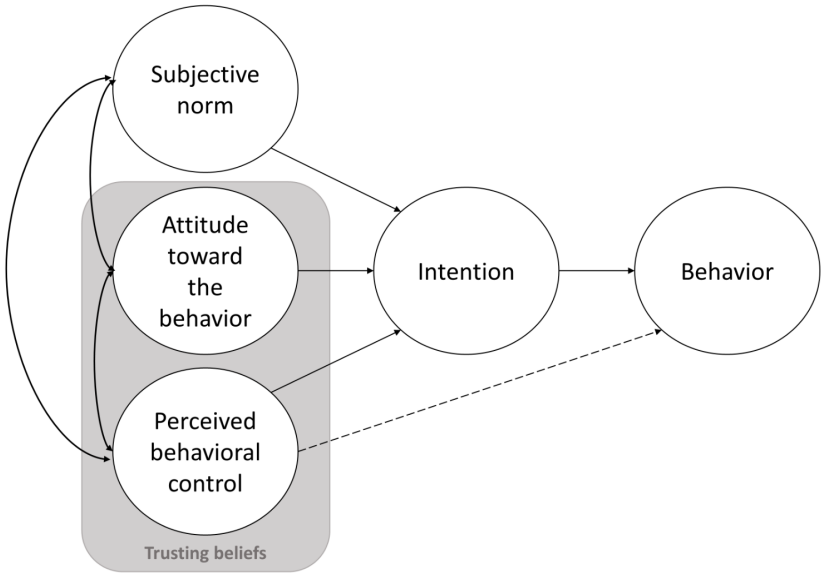

Fig. 1 Theory of planned behavior (adapted from Ajzen, 1991)

However, it is necessary to integrate this methodological triplet to accept that a behavior is generated by more real causes. In this paper, we study the dynamics of behavior in a group as an emergent process caused by agents' decisions about e-commerce adoption, based on the TPB (Ajzen, 1991) and using the coordination game. Our research question is: what is the effect of the topology of the multiplex network when deciding to make transactions through virtual or physical channels? Answering this question through the chosen methodological synergy will help to understand the emerging behavior and the real reasons for it.

\section{Related work}

Table 1 presents a review of studies related to the simulation of e-commerce adoption processes (Delre et al., 2010; Jiang et al., 2016; Jiang et al., 2018; Kuandykov and Sokolov, 2010; Lee and Son, 2020; Ramezanian et al., 2015; Serrano and Iglesias, 2016; Wu et al., 2018). We selected the articles that give details about the modeling process.

The articles have a great variety of characteristics and propose theories about the modeling process. Social influence occurs mainly through neighbors' effect on a utility or probability function of making the transaction; the agents decide primarily using that function and a threshold: if the function takes a value that passes the threshold, the agent makes the transaction. There is only one study that includes a multiplex network, and it only considers the random type. The other studies use one single network at once.

Despite the variety of elements on cited works, there is still a lack of a detailed model with a close synergy between three realistic aspects of social development: TPB, complex networks, and game theory. Our work helps to understand the impact of the different social structures on the observed behaviors within decision-making for a transaction. 
Table 1 Studies related to the simulation of e-commerce adoption processes

\begin{tabular}{|c|c|c|c|}
\hline Reference & Social influence & Decision rule & Network treatment \\
\hline Kuandykov and Sokolov (2010) & $\begin{array}{c}\text { The probability of adoption increases } \\
\text { with the number of social neighbors that } \\
\text { make the transaction }\end{array}$ & Probability function & $\begin{array}{l}\text { Single network: preferential } \\
\text { attachment and random }\end{array}$ \\
\hline Delre et al. (2010) & $\begin{array}{c}\text { The utility of adoption increases with } \\
\text { the number of social neighbors that } \\
\text { make the transaction }\end{array}$ & $\begin{array}{l}\text { Heuristic: agent adopts if the } \\
\text { evaluation pass the utility } \\
\text { threshold }\end{array}$ & $\begin{array}{l}\text { Single network: preferential } \\
\text { attachment }\end{array}$ \\
\hline Ramezanian et al. (2015) & Coordination game & $\begin{array}{l}\text { Heuristic: agent adopts if the } \\
\text { evaluation of the product passes } \\
\text { the utility threshold }\end{array}$ & Multiplex: random \\
\hline Jiang et al. (2016) & $\begin{array}{l}\text { The utility increases with the number of } \\
\text { actual buyers in the network }\end{array}$ & $\begin{array}{l}\text { Heuristic: agent adopts if the } \\
\text { evaluation of the product passes } \\
\text { the utility threshold }\end{array}$ & $\begin{array}{l}\text { Single network: preferential } \\
\text { attachment }\end{array}$ \\
\hline Serrano and Iglesias (2016) & Rumor diffusion & Probability function & $\begin{array}{c}\text { Single network: preferential } \\
\text { attachment }\end{array}$ \\
\hline Wu et al. (2018) & $\begin{array}{l}\text { Neighbor influence factor as a function } \\
\text { of out-degree of the nodes }\end{array}$ & Adoption rate & Single network: no specified \\
\hline Jiang et al. (2018) & $\begin{array}{c}\text { The utility of adoption increases with } \\
\text { the number of social neighbors that } \\
\text { make the transaction }\end{array}$ & $\begin{array}{l}\text { Heuristic: agent adopts if the } \\
\text { evaluation of the product passes } \\
\text { the utility threshold }\end{array}$ & $\begin{array}{l}\text { Scenarios with single networks: } \\
\text { preferential attachment, } \\
\text { random, and small-world }\end{array}$ \\
\hline Lee and Son (2020) & $\begin{array}{l}\text { Neighbor influence factor as a function } \\
\text { of out-degree of the nodes }\end{array}$ & $\begin{array}{l}\text { Decision Field Theory with } \\
\text { Learning (DFT-L) }\end{array}$ & $\begin{array}{l}\text { Scenarios with single networks: } \\
\text { ring, random, and small-world }\end{array}$ \\
\hline
\end{tabular}

\section{Simulation model}

To evaluate the effect of the multiplex network's topology on the diffusion process, we developed a simulation model at the individual level. According to the diffusion process, there are two categories: epidemic-like and decision-based models (Salehi et al., 2015). To the former category belong the processes where the probability that a node acquires a particular state (infected, for example) is determined by the state of its adjacent nodes. To the latter category belong the processes where each node decides to adopt a particular state or behavior depending on the state or behavior of its adjacent nodes. The decision-based category is our interest, and it has an approach called the direct-benefit effect. The approach assumes that there is a specific payoff from copying the decisions of others (Ramezanian et al., 2015; Salehi et al., 2015). Through this Section 3, we describe our model, where people get a payoff according to a matrix, after having decided to make or not the transaction, and by what channel.

The model is composed of a group of people, where, in each time step, they decide to make a virtual, physical, or null transaction. This model is built for the case where each individual can acquire the same product or service through one channel or another. It happens when organizations become dual-channel to gain a larger market share. We developed the model in NetLogo ${ }^{\circledR}$, and in Fig. 2, we present the general structure.

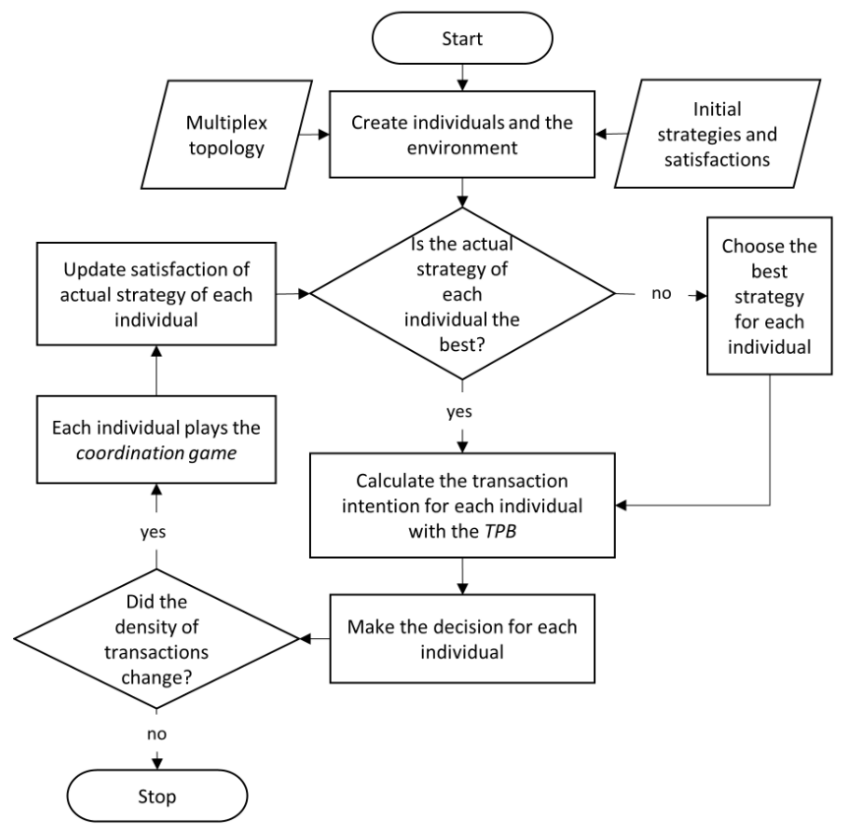

Fig. 2 Model algorithm

At the beginning of each simulation, a network topology must be configured for each channel. Since empirical data are not available, three types of networks can be configured: small-world, preferential attachment, and random. A single person belongs to $n$ social networks at the same time. In this case, $n$ depends on the channel to make the transaction: if physical or virtual, then $n=2$ (see the example in Fig. 3): 
- Network $0(n=0)$ : Friends who make a virtual transaction, and

- ii) network $1(n=1)$ : friends who make a physical transaction.

Each individual $j$ will have a fixed number of friends $f_{i}$ through the simulation, which can be connected by any network $n$. Then, $f_{j n}$ is the number of friends of individual $j$ in network $n$.

At each time step, individuals will decide whether to make a transaction and if so, which channel they will use to do it. The choice made by the individual about the channel (virtual or physical) as to whether he/she will make the transaction depends on his/her intention, and this was represented while considering the TPB model proposed by (Ajzen, 1991).

After the decision is made, individuals calculate their satisfaction through a coordination game, and the simulation stops when there is no more change in decisions.

\subsection{Strategies definition}

Each individual $j$ has a fixed matrix of $M$ strategies he/she will take over the simulation. It is composed of the weights given to the constructs and the selection of the channel, as shown in Eq. (1):

Strategies $_{j}=\left[W_{j} \boldsymbol{N}_{j}\right]$.

At each time step, each individual will select one strategy (one single row of the matrix $W_{j}$ of Eq. (2) and one single value of the vector $N_{j}$ of Eq. (3)), which will serve to calculate the intention to make a transaction. $w_{m, i}$ is the weight of the strategy $m$ to the construct $i$. Every value of the matrix is normally distributed, with a mean and standard deviation defined by parameters presented in Subsection 3.4.

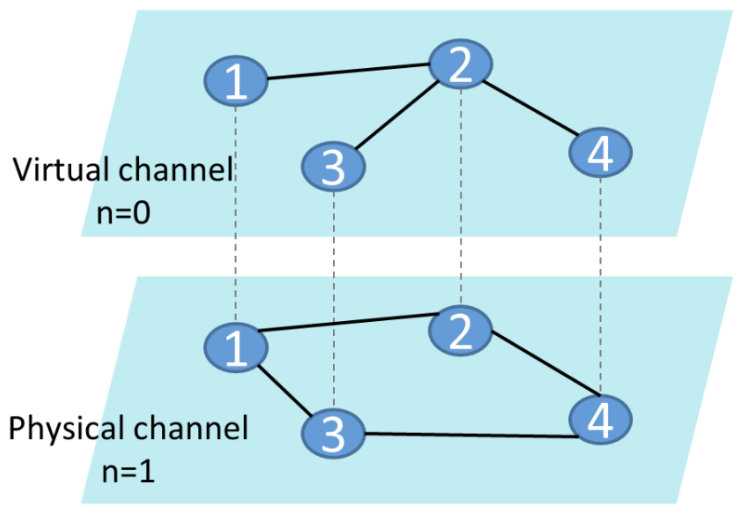

Fig. 3 Example of a multiplex network with four individuals
$W_{j}=\left[\begin{array}{cc}w_{0,0} & w_{0,1} \\ \vdots & \vdots \\ w_{M, 0} & w_{M, 1}\end{array}\right] m=0,1, \ldots, M$

Each pair of weights is used in a particular channel. The next fixed vector represents the channel or network $n$ where the individual will make the transaction.

$\boldsymbol{N}_{j}=\left[\begin{array}{c}n_{0} \\ \vdots \\ n_{M}\end{array}\right], n=0,1, m=0,1, \ldots, M$

At the beginning of the simulation, it is defined the satisfaction vector $\boldsymbol{S}_{j t}$ with $M$ normally distributed values as Eq. (4), but it is updated at every time step with the new satisfaction value (as shown in Subsection 3.4). This vector serves as a measure of the goodness of each strategy. If $s_{m}$ is the highest value of the vector $\boldsymbol{S}_{j t}$ in time $t-1$, the individual will choose the row $m$ of Strategies $_{j}$ matrix in time $t$.

$\boldsymbol{S}_{j t}=\left[\begin{array}{c}s_{0} \\ \vdots \\ s_{M}\end{array}\right], m=0,1, \ldots, M$

\subsection{Calculation of the intention and decision making}

In this study, the intention to make a transaction will depend on the following two constructs.

\subsubsection{Trusting beliefs $\left(T_{n}\right)$}

This element (which we call macro-construct) brings together two of the TPB constructs: attitude toward the behavior and perceived behavioral control. We have done the union because trust is an antecedent that positively influences both constructs (Pavlou and Fygenson, 2006). Also, the attitude towards behavior and perceived behavioral control are free parameters. Then, we can condense their information in a single free parameter, which allows simplifying the model.

The attitude toward the behavior is the result of the feeling the individual has about the usefulness of carrying out a certain behavior (Davis, 1989), in this case, how useful each individual considers to perform their transactions virtually or physically. And the perceived behavioral control is associated with the individual judgments of an agent's capabilities to perform a behavior (Pavlou and Fygenson, 2006), in this case, how well qualified each individual feels to carry out their transactions virtually or physically. While channels improve the ease of use and show the usefulness, these constructs increase their value. 
Here we propose the macro-construct $T_{n}$ as a fixed value of trust through the channel $n$, given at the beginning of the simulation.

\subsubsection{Subjective norm $\left(\mathrm{SN}_{j}\right)$}

Social influence or subjective norm refers to perceived pressures from social networks to make or not to make a certain behavioral decision (Lu et al., 2005). This vale is calculated according to the number of friends who made the same decision (to make the transaction, using the same channel), over the total of friends on the channel, as Eq. (5):

$$
S N_{j t n}=\frac{\operatorname{tran}_{f j n}}{f_{j n}},
$$

where $\operatorname{tran}_{f j n}$ is the total number of transactions made by the friends of individual $j$ through the channel $n$. The intention of the individual $j$ to make a transaction in a period $t$ through the channel $n$, is calculated as a linear combination of trust (attitude and perceived behavioral control) and subjective norm and as previously exposed (see Eq. (6)). This intention takes into account the characteristic of the product or service in a specific channel $\left(T_{n}\right)$, the social influence of his/her friends in a particular channel $\left(S N_{j t n}\right)$, and the measure of how much the individual cares about trust and social influence $\left(w_{m, i}\right)$.

$$
I_{j t n}=W_{m, 0} * T_{n}+W_{m, 1} * S N_{j t n}
$$

In Eq. (6), $I_{j t n}$ is the intention of the individual $j$ to make a transaction at the period through the channel $n$. Notice that $I_{j t n} \in[0,1]$, hence, the individual will choose to make a transaction with a probability of $I_{j t n}$. Every individual $j$ has a fixed threshold $k$ with which he/she will decide if he/ she makes the transaction. Then, if $I_{j t n}>k_{j}$, the individual will choose to make the transaction.

\subsection{The satisfaction of the selected strategy}

The behavior of individuals widely depends on their family or friends: the more people adopt a behavior, the more motivated the individual will be to choose it. This consideration is well studied under the light of game theory, specifically through the coordination game (Nisan et al., 2007). In the model, after all the individuals have made the decision, they proceed to play the 2-player coordination game, well used to analyze diffusion processes (Immorlica et al., 2007; Ramezanian et al., 2015). Each individual will play the game with all his/her friends $f_{j}$, independent of the choice they have made. In this sense, the individual $j$ will earn a payoff $p_{j c}$, where $c$ is the person connected with the individual $j$. Table 2 includes the payoff of the game, where $\alpha>0, \beta>0$, and $\alpha>\beta$.

Then, the satisfaction $s$ of the individual $j$ with the strategy $m$ is calculated as follows in Eq. (7):

$s_{j m}=\frac{\sum_{c=1}^{f_{j}} p_{j c}}{f_{j}}$,

where $f_{j}$ is the total of friends of individual $j$, and $p_{j c}$ is the value earned in each game played. For every time step, the position $m$ of the $\boldsymbol{S}_{j t}$ vector is updated with the current value of $s_{j m}$.

\subsection{Parametrization and scenario's design}

As we aim to understand a particular phenomenon instead of predicting behavior, we use a generic parametrization, described in Table 3 (preferential attachment network is constructed as mentioned in Subsection 2.3).

We define the scenarios by the combination of the three network topologies: random, small-world, and preferential attachment, for the virtual and physical network $(n=0$, $n=1)$. We choose six possible combinations or scenarios, as shown in Table 4. For each case, since the subjective norm $S N_{j t}$ is an endogenous variable, we discriminate the scenarios by the values of trust $T_{0}$ in the virtual network.

Notice that subjective norm $S N_{j t}$ is outside companies' control, but they can still implement strategies to improve the trust in a particular network. In this case, we consider

\begin{tabular}{|c|c|c|c|c|}
\hline & & \multicolumn{3}{|c|}{ Friend's decision } \\
\hline & & $\begin{array}{c}\text { Virtual } \\
\text { transaction }\end{array}$ & $\begin{array}{c}\text { Physical } \\
\text { transaction }\end{array}$ & $\begin{array}{c}\text { No } \\
\text { transaction }\end{array}$ \\
\hline \multirow{3}{*}{$\begin{array}{l}\text { Individual's } \\
\text { decision }\end{array}$} & $\begin{array}{c}\text { Virtual } \\
\text { transaction }\end{array}$ & $\alpha$ & $\beta$ & 0 \\
\hline & $\begin{array}{c}\text { Physical } \\
\text { transaction }\end{array}$ & $\beta$ & $\alpha$ & 0 \\
\hline & $\begin{array}{c}\text { No } \\
\text { transaction }\end{array}$ & 0 & 0 & $\alpha$ \\
\hline
\end{tabular}

Table 2 Payoff matrix of a coordination game

Table 3 Parameterization of the model for the base scenario

\begin{tabular}{lc}
\hline Parameter & Value \\
\hline Population size (static) & 100 \\
Number of possible strategies $M$ & 10 \\
Mean weight of trust $W_{m, 0}$ and subjective norm $W_{m, 1}$ & 0.5 \\
$\begin{array}{l}\text { Standard deviation weight of trust } W_{m, 0} \text { and subjective } \\
\text { norm } W_{m, 1}\end{array}$ & 0.3 \\
Threshold $k$ & 0.5 \\
Connection probability for random network & 0.1 \\
Probability of rewiring in a small world network & 0.1 \\
\hline
\end{tabular}


Table 4 Scenario design by network topologies combination

\begin{tabular}{lcc}
\hline Scenario & Virtual network $(n=0)$ & Physical network $(n=1)$ \\
\hline 1 & Preferential Attachment (PA) & Preferential Attachment (PA) \\
2 & Small World (SM) & Small World (SM) \\
3 & Preferential Attachment (PA) & Small World (SM) \\
4 & Random (R) & Random (R) \\
5 & Random (R) & Preferential Attachment (PA) \\
6 & Random (R) & Small World (SM) \\
\hline
\end{tabular}

Table 5 Scenario discrimination by trust in the virtual network $(n=0)$

\begin{tabular}{|c|c|c|c|c|}
\hline 0.0 & 0.25 & 0.5 & 0.75 & 1 \\
\hline $\begin{array}{l}\text { Null trust } \\
\text { in the } \\
\text { virtual } \\
\text { network }\end{array}$ & $\begin{array}{c}\text { Low trust in } \\
\text { the virtual } \\
\text { network }\end{array}$ & $\begin{array}{l}\text { Medium } \\
\text { trust in } \\
\text { the virtual } \\
\text { network }\end{array}$ & $\begin{array}{l}\text { High trust } \\
\text { in the } \\
\text { virtual } \\
\text { network }\end{array}$ & $\begin{array}{l}\text { Full trust } \\
\text { in the } \\
\text { virtual } \\
\text { network }\end{array}$ \\
\hline
\end{tabular}

five scenarios of trust in the virtual network $(n=0)$, as shown in Table 5, and for each case, we make a parameter sweep of trust in the physical network $(n=1)$. It is, we present the behavior of the transactions keeping fixed the trust in the virtual network, combined with all possible values of trust in the physical one.

\subsection{Verification and validation}

Verification and validation are processes used to provide confidence in simulation models: verification determines whether the conceptual model has been implemented correctly, whereas validation determines whether the conceptual model is an adequate representation of reality (Sargent, 2011; Xiang et al., 2005). We performed the techniques: extreme conditions test, conceptual model validation, face validity, internal validity, and sensitivity analysis. All the above-mentioned techniques yielded adequate results to proceed with the experimentation.

\section{Results}

\subsection{General behavior}

We now present the results of 400 simulations per each parameter combination. There is a common behavior in all outputs: at first, and independently of the parameters used in the simulation, individuals change their strategies looking for maximizing payments, and after about 10 time steps (40, when using the preferential attachment structure) they coordinate their decision to make or not the transaction. The difference is that if they make the transaction, they can choose different channels. Due to coordination, we are interested in observing the state in which the system is stabilized.
Important measures when analyzing networks are the average degree and the average shortest path length. The first one is a measure of connectivity: the number of edges (or friends) connected to each node (Watts and Strogatz 1998). The second one is a measure between two nodes, and it is the path with the minimum number of edges. It is a measure of the efficiency of information transfer on a network: the smaller the value, the more easily the information is spread through the network (Boccaletti et al., 2006). Table 6 presents the mean of these values by topology, calculated after running simulations. In this case, the most connected and the most efficient topology networks are random (R) and small-world (SW). In Subsection 4.3, we use this information to analyze some results.

\subsection{Scenarios analysis}

The results are based on three indicators:

1. the density of virtual transactions $d_{v t}$ in Eq. (8),

2. the density of total transactions $d_{t}$ in Eq. (9), and

3. average intention to make the transaction $a I$ in Eq. (10):

$d_{v t}=\frac{\text { virtual transactions }}{\text { total transactions }}$,

$d_{t}=\frac{\text { total transactions }}{\text { total of individuals }}$,

$a I=\frac{\sum I_{j}}{\text { total of individuals }}$.

Fig. 4 present results for each scenario of topologies according to the trust scale in Table 4. Blue points close to 0 in the $y$-axis mean that all transactions were made in the physical network; blue points close to 1 in y-axis say that all transactions were made in the virtual network; no blue points mean that there was no transaction. Black lines are the average density of virtual transactions, and red lines are the density of total transactions. For all scenarios,

Table 6 Average degree (AD) and average shortest path length (ASPL) by network topology

\begin{tabular}{lcccc}
\hline $\begin{array}{l}\text { Type of } \\
\text { network }\end{array}$ & $\begin{array}{c}\text { Mean } \\
\text { AD }\end{array}$ & $\begin{array}{c}\text { Standard } \\
\text { deviation AD }\end{array}$ & $\begin{array}{c}\text { Mean } \\
\text { ASPL }\end{array}$ & $\begin{array}{c}\text { Standard } \\
\text { deviation ASPL }\end{array}$ \\
\hline $\begin{array}{l}\text { Random (R) } \\
\text { Small World }\end{array}$ & 10 & 0.421 & 1.98 & 0 \\
(SW) & 9.899 & 0 & 2.239 & 0.061 \\
$\begin{array}{l}\text { Preferential } \\
\text { Attachment } \\
\text { (PA) }\end{array}$ & 5.365 & 0.471 & 2.712 & 0.036 \\
\hline
\end{tabular}


a)

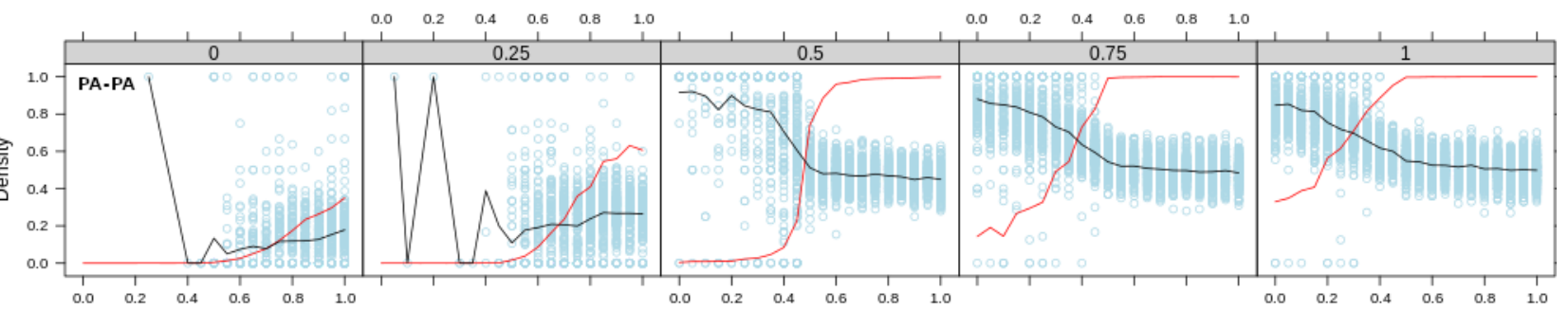

b) 紊
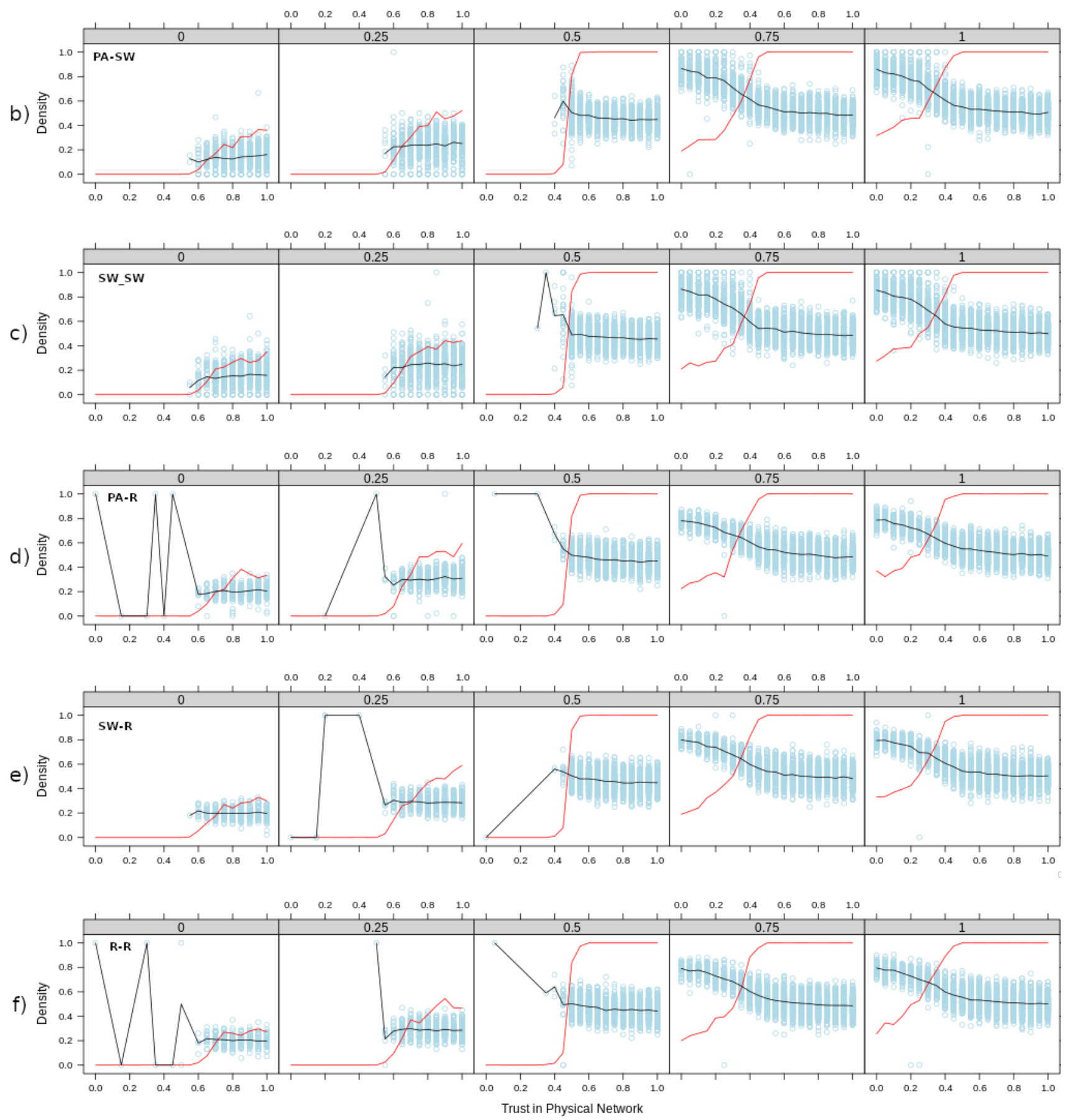

Fig. 4 Density of virtual transactions per combination topology; a) PA vs. PA; b) PA vs. SW; c) SW vs. SW; d) PA vs. R; e) SW vs. R; f) R vs. R. (Blue points are $d_{v t}$, the black line is the average of $d_{v t}$, and the red line is $d_{t}$ ) 
$T_{0}=T_{1}=0.5$ is the critical point where the population turns from not making transactions to making them (red line). This is the expected inflection point because the threshold $k$ was defined in this same number. Also notice that, where both trust constructs are approaching to 1 , it is expected that the density of virtual transaction $d_{v t}$ reaches a mean of 0.5 (the variability is given by the set of strategies), because it is indifferent which of the two networks to choose since both have high trust.

In Fig. 4(a), where both networks are PA and for values of $T_{n}<0.5$, there are structures where the densities turn towards extreme values $-d_{v t}$ equal to 1 or 0 - and they are scattered. Density values equal to 1 or 0 means there was full coordination: all transactions were made in the virtual network, or all transactions were made in the physical network.

This is because, in the PA topology, there are few individuals influencing the channel selection of their friends (all population tends to choose the same network). In other words, there are influencers guiding the dynamics of the network. Although there was total coordination among all individuals (in no other scenario, it appears this phenomenon), this occurred on a few occasions. Scattered densities show that channel selection of individuals is uncertain and difficult to predict. This result is consequent with Delre et al. (2010), which explain that PA markets (represented in a single network) with high social influence are more unpredicatble, and guided by highly connected agents. But what happens with the dynamics if one of the topologies is changed in the multiplex?

Fig. 4(b) presents an important case, where the two topologies for excellence of social networks are combined: PA and SW. It seems that the presence of SW structures cancels the effect of the influencing individuals of PA. Table 6 shows that SW is most connected than PA, and it has a smaller average shortest path length. The smaller the measure, the less dispersed is the dynamic in channel selection, i.e., the smallest the shortest path length, the easiest the information is spread through the network (easier to synchronize in the channel selection). From here, we interpret that the presence of a network with a high average degree and small average shortest path length can dominate the dynamics of the entire system.

Fig. 4(c) shows the case where both networks are SW. It is observed a dynamic a little less dispersed than the previous case. This phenomenon is because the multiplex follows structures with smaller average shortest path length. In this case, there is no dominant network since both are equal.

There is a common factor from Fig. 4(d) to (f): the random structure in at least one network. As shown in Table 6, the random topology has the smallest average shortest path length. As this network is the most efficient, all the others that are connected to it will decrease its dispersion. The average shortest path length is what dominates the dispersion: if an R network appears (shorter paths), then the dynamics is less scattered. This behavior is clearer in cases when $0<d_{t}<1$ : Fig. 4(a), (b) and (c) are more scattered than Fig. 4(d), (e) and (f).

In the case of the SW structure, when it is accompanied by an R network, as shown in Fig. 4(e), the density of virtual transactions is less dispersed than the case when both are SW (Fig. 4(c)). Here, as the SW structure is less efficient than the $\mathrm{R}$, the last one is which dominates the dynamics or the system.

The last scenario is shown in Fig. 4(f), where both R networks are involved. This combination is the most efficient case because multiplex has the smallest average shortest path length, and it has no dominant structure since both are equal. By looking solely at the average values of all scenario results, we do not find a big difference between the densities across all scenarios. Instead, our findings present a significant influence of the structures in the uncertainty.

Fig. 5 presents the average intention to make the transaction for all scenarios. When trust construct in physical network is low (the two left squares of Fig. 5), the presence of random structures and high values in trust construct in virtual network, the intention to make a transaction is higher than scenarios with other structures and

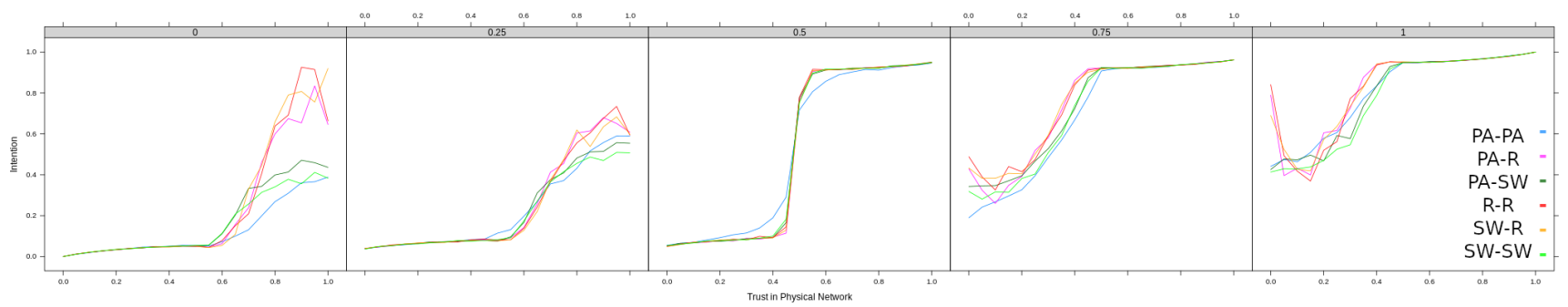

Fig. 5 Average intention to make the transaction 
low values in trust construct in virtual network. This phenomenon occurs because when connectivity is higher, the flow of information is more efficient, and there is greater coordination among the members of the network. This coordination is reflected in a greater value of the subjective norm, and finally, in a greater value of the intention. This result coincides with (Bohlmann et al., 2010), who explain that more connected networks are more likely to spread innovation.

\subsection{Practical insights}

Organizations have two options if they wish to increase the transactions using any channel: on the one hand, the invest resources in trust, understood as improved ease of use, and apparent usefulness. On the other hand, the other option is to invest resources in decreasing the average shortest path length of the network, by increasing connectivity. The results show that there is an appropriate cost-benefit relationship regarding investment in connectivity when $T_{n}<0.5$ in at least one network; otherwise, the investment will not have sufficient impact to increase the current transactions.

In cases where PA structures are present and the influencing node is known (the most connected individual), strategies which aim at improving the intention of this node are quite effective in generating more coordination throughout the network. If a manager knows that market has poor connections, it is required a careful selection of influencers that generate positive effects in transactions. However, in cases with the presence of SW or R structures, it is more effective to increase coordination by increasing connectivity. In general, the more coordination, the less uncertainty.

Finally, policies focused on increasing connectivity or trust in any network will have a positive impact on the other one. This synergic effect happens because each individual plays the coordination game with all his/her friends, regardless of the network in which they are.

\section{Conclusions}

Studies on the impact of social multiplex networks on the adoption of technologies such as e-commerce are scarce. Since real transactions do not occur in a simplistic network, by separating the dynamics into their characteristic structural networks, one can achieve more precise and richer dynamics. Then, the direction of research must change from "what network represents the phenomenon" to "what network combination represents the phenomenon." This article presents an important methodological contribution by showing a new way to analyze the impact of social networks on multiplex structures closer to reality, as well as a practical contribution by evidencing the effects of the structure both on the intention and on the decision to carry out transactions. We particularly wish to emphasize the practical findings: these highlight when it is worth investing in the construct of subjective norm, understood as connectivity, and when it is worth investing in the construct of trust. The application of the findings would imply that organizations have a good understanding of their market.

We found that connectivity is a key issue when trying to understand and manage a market's behavior. The more connected individuals are, the more efficient the flow of information is, and this translates into greater coordination in the decisions they made. When a multiplex is formed by at least one network with a very efficient information flow, this network will govern the dynamics of the competition between the channels selection and reduce the uncertainty. What a company will see when investing in the connectivity of its customers is less uncertainty in the number of transactions and more intention to make them. Less uncertainty, which is implied by the structure of the network, helps with strategic and financial planning, and more intention makes it easier to translate intention into action.

We also found a practical relationship between the constructs: as the effect of the subjective norm (social influence) decreases as the values of trust increase, organizations must estimate the values of the constructs to know when and how an investment can materialize in transactions. With high values of social influence, a company could sacrifice some trust. In turn, investing in social influence is worthwhile when trust is low in at least one channel; otherwise, it does not have enough impact to increase current transactions.

As a limitation of this work, it is evident that both channels have been defined with the same characteristics to present generic results. For future work, we propose to characterize both networks with properties inherent to them and thus have more realistic models. Other elements that can offer a richer dynamic are the use of dynamic networks, since people change their friends over time, and the use of empirical networks, because social networks may follow structures different from those presented in this work. 


\section{References}

Ajzen, I. (1991) "The theory of planned behavior", Orgnizational Behavior and Human Decision Processes, 50(2), pp. 179-211. https://doi.org/10.1016/0749-5978(91)90020-T

Aydın, E., Savrul, B. K. (2014) "The Relationship between Globalization and E-commerce: Turkish Case", Procedia - Social and Behavioral Sciences, 150, pp. 1267-1276. https://doi.org/10.1016/J.SBSPRO.2014.09.143

Bánhidi, Z. (2021) "The Impact of Broadband Networks on Growth and Development in South America", Periodica Polytechnica Social and Management Sciences, 29(1), pp. 33-39. https://doi.org/10.3311/PPso.14905

Barabási, A. L., Oltvai, Z. N. (2004) "Network biology: understanding the cell's functional organization", Nature Reviews Genetics, 5(2), pp. 101-113. https://doi.org/10.1038/nrg1272

Boccaletti, S., Latora, V., Moreno, Y., Chavez, M., Hwang, D. U. (2006) "Complex networks: Structure and dynamics", Physics Reports, 424(4-5), pp. 175-308. https://doi.org/10.1016/j.physrep.2005.10.009

Bohlmann, J. D., Calantone, R. J., Zhao, M. (2010) "The Effects of Market Network Heterogeneity on Innovation Diffusion: An Agent-Based Modeling Approach", Journal of Product Innovation Management, 27(5), pp. 741-760. https://doi.org/10.1111/j.1540-5885.2010.00748.x

Cadavid, D. L. (2015) "Aproximación metodológica al análisis de la difusión de innovaciones en productos que utilizan tecnologías limpias considerando elecciones individuales de adopción" (Methodological approach to the analysis of the diffusion of diffusion of product innovations using clean technologies technologies considering individual choices of adoption), $\mathrm{PhD}$ Thesis, Universidad Nacional de Colombia, Sede Medellín. [online] Available at: https://repositorio.unal.edu.co/handle/unal/52700 [Accessed: 15 June 2019] (in Spanish)

Davis, F. D. (1989) "Perceived Usefulness, Perceived Ease of Use, and User Acceptance of Information Technology", MIS Quarterly, 13(3), pp. 319-340. https://doi.org/10.2307/249008

de Solla Price, D. J. (1965) "Networks of Scientific Papers: The patterns of bibliographic references indicates the nature of the scientific research front", Science, 149(3683), pp. 510-515. https://doi.org/10.1126/science.149.3683.510

DeLone, W. H., McLean, E. R. (2004) "Measuring e-Commerce Success: Applying the DeLone \& McLean Information Systems Success Model", International Journal of Electronic Commerce, 9(1), pp. 31-47. https://doi.org/10.1080/10864415.2004.11044317

Delre, S. A., Jager, W., Bijmolt, T. H. A., Janssen, M. A. (2010) "Will it Spread or Not? The Effects of Social Influences and Network Topology on Innovation Diffusion", Journal of Product Innovation Management, 27(2), pp. 267-282. https://doi.org/10.1111/j.1540-5885.2010.00714.x

Eastin, M. S. (2002) "Diffusion of e-commerce: an analysis of the adoption of four e-commerce activities", Telematics and Informatics, 19(3), pp. 251-267. https://doi.org/10.1016/S0736-5853(01)00005-3
Erdős, P., Rényi, A. (1959) "On Random Graphs", Publicationes Mathematicae, 6, pp. 290-297.

Faloutsos, M., Faloutsos, P., Faloutsos, C. (1999) "On power-law relationships of the Internet topology", ACM SIGCOMM Computer Communication Review, 29(4), pp. 251-262. https://doi.org/10.1145/316194.316229

Grandon, E. E., Pearson, J. M. (2004) "Electronic commerce adoption: an empirical study of small and medium US businesses", Information \& Management, 42(1), pp. 197-216. https://doi.org/10.1016/J.IM.2003.12.010

Ha, K. H., Canedoli, A., Baur, A. W., Bick, M. (2012) "Mobile banking — insights on its increasing relevance and most common drivers of adoption", Electronic Markets, 22(4), pp. 217-227. https://doi.org/10.1007/s12525-012-0107-1

Immorlica, N., Kleinberg, J., Mahdian, M., Wexler, T. (2007) "The role of compatibility in the diffusion of technologies through social networks", In: EC '07: Proceedings of the 8th ACM Conference on Electronic Commerce, San Diego, CA, USA, pp. 75-83. https://doi.org/10.1145/1250910.1250923

Jiang, G., Tadikamalla, P. R., Shang, J., Zhao, L. (2016) "Impacts of knowledge on online brand success: an agent-based model for online market share enhancement", European Journal of Operational Research, 248(3), pp. 1093-1103. https://doi.org/10.1016/j.ejor.2015.07.051

Jiang, G., Liu, S., Liu, W., Xu, Y. (2018) "Agent-based modeling and simulation of the decision behaviors of e-retailers", Industrial Management \& Data Systems, 118(5), pp. 1094-1113. https://doi.org/10.1108/IMDS-07-2017-0321

Kivelä, M., Arenas, A., Barthelemy, M., Gleeson, J. P., Moreno, Y., Porter, M. A. (2014) "Multilayer networks", Journal of Complex Networks, 2(3), pp. 203-271. https://oi.org/10.1093/comnet/cnu016

Kuandykov, L., Sokolov, M. (2010) "Impact of social neighborhood on diffusion of innovation S-curve", Decision Support Systems, 48(4), pp. 531-535. https://doi.org/10.1016/j.dss.2009.11.003

Latora, V., Marchiori, M. (2002) "Is the Boston subway a small-world network?", Physica A: Statistical Mechanics and Its Applications, 314(1-4), pp. 109-113. https://doi.org/10.1016/S0378-4371(02)01089-0

Lee, S., Son, Y. J. (2020) "Extended decision field theory with social-learning for long-term decision-making processes in social networks", Information Sciences, 512, pp. 1293-1307. https://doi.org/10.1016/j.ins.2019.10.025

Lu, J., Yao, J. E., Yu, C. S. (2005) "Personal innovativeness, social influences and adoption of wireless Internet services via mobile technology", The Journal of Strategic Information Systems, 14(3), pp. $245-268$. https://doi.org/10.1016/j.jsis.2005.07.003

MacVaugh, J., Schiavone, F. (2010) "Limits to the diffusion of innovation: A literature review and integrative model", European Journal of Innovation Management, 13(2), pp. 197-221. https://doi.org/10.1108/14601061011040258 
Newman, M. E. J. (2001) "The structure of scientific collaboration networks", Proceedings of the National Academy of Sciences of the United States of America, 98(2), pp. 404-409. https://doi.org/10.1073/pnas.98.2.404

Ngai, E. W. T., Wat, F. K. T. (2002) "A literature review and classification of electronic commerce research", Information \& Management, 39(5), pp. 415-429. https://doi.org/10.1016/S0378-7206(01)00107-0

Nisan, N., Roughgarden, T., Tardos, É., Vazirani, V. (2007) "Algorithmic Game Theory", [pdf] Cambridge University Press, New York, NY, USA. Available at: https://www.cs.cmu.edu/ sandholm/cs15892F13/algorithmic-game-theory.pdf [Accessed: 21 November 2020]

Pavlou, P. A., Fygenson, M. (2006) "Understanding and Predicting Electronic Commerce Adoption: An Extension of the Theory of Planned Behavior", MIS Quarterly, 30(1), pp. 115-143. https://doi.org/10.2307/25148720

Petridis, K., Petridis, N. E. (2020) "Diffusion of Innovations in Middle Eastern versus Western Markets: A Mathematical Computation Cellular Automata Simulation Model", Operational Research. https://doi.org/10.1007/s12351-020-00598-y

Rahmandad, H., Sterman, J. (2008) "Heterogeneity and Network Structure in the Dynamics of Diffusion: Comparing Agent-Based and Differential Equation Models", Management Science, 54(5), pp. 998-1014. https://doi.org/10.1287/mnsc.1070.0787

Ramezanian, R., Magnani, M., Salehi, M., Montesi, D. (2015) "Diffusion of innovations over multiplex social networks", In: 2015 The International Symposium on Artificial Intelligence and Signal Processing (AISP), Mashhad, Iran, pp. 300-304. https://doi.org/10.1109/AISP.2015.7123501

Salehi, M., Sharma, R., Marzolla, M., Magnani, M., Siyari, P., Montesi, D. (2015) "Spreading Processes in Multilayer Networks", IEEE Transactions on Network Science and Engineering, 2(2), pp. 65-83. https://doi.org/10.1109/TNSE.2015.2425961
Sargent, R. G. (2011) "Verification and validation of simulation models", [pdf] In: 2011 Winter Simulation Conference, Phoenix, AZ, USA, pp. 183-198. Available at: http://www.informs-sim.org/wsc11papers/016.pdf [Accessed: 21 November 2020]

Serrano, E., Iglesias, C. A. (2016) "Validating viral marketing strategies in Twitter via agent-based social simulation", Expert Systems with Applications, 50, pp. 140-150. https://doi.org/10.1016/j.eswa.2015.12.021

Sporns, O. (2003) "Network Analysis, Complexity, and Brain Function", Complexity, 8(1), pp. 56-60. https://doi.org/10.1002/cplx.10047

Verbrugge, L. M. (1979) "Multiplexity in Adult Friendships", Social Forces, 57(4), pp. 1286-1309. https://doi.org/10.1093/sf/57.4.1286

Watts, D. J., Strogatz, S. H. (1998) "Collective dynamics of 'small-world' networks", Nature, 393(6684), pp. 440-442. https://doi.org/10.1038/30918

Wu, L., Liu, Q., Hong, R., Chen, E., Ge, Y., Xie, X., Wang, M. (2018) "Product Adoption Rate Prediction in a Competitive Market", IEEE Transactions on Knowledge and Data Engineering, 30(2), pp. 325-338. https://doi.org/10.1109/TKDE.2017.2763944

Wymer, S. A., Regan, E. A. (2005) "Factors Influencing e-commerce Adoption and Use by Small and Medium Businesses", Electronic Markets, 15(4), pp. 438-453. https://doi.org/10.1080/10196780500303151

Xiang, X., Kennedy, R., Madey, G., Cabaniss, S. (2005) "Verification and Validation of Agent-based Scientific Simulation Models", [pdf] In: 2005 Agent-Directed Simulation Symposium (ADS'05), San Diego, CA, USA, pp. 47-55. Available at: http://www3. nd.edu/ nom/Papers/ADS019_Xiang.pdf [Accessed: 04 July 2019] 